\title{
Creating Cultural and Historical Imaginaries in Physical Space: Worldbuilding in Chinese Theme Parks
}

\author{
Carissa Baker \\ University of Central Florida, Orlando, USA
}

\begin{abstract}
Theme parks are fascinating texts built on spatial narratives and detailed storyworlds. Worldbuilding and subcreation are literal in these spaces, but they likewise contain symbolic experiences that represent cultural and historical imaginaries. China is one of the largest markets in the global theme park industry. The design ethos in many parks is to represent fantasy versions of reality or depict cultural beliefs. This article offers analysis of examples in Chinese parks that signify simulated place or culture (for example, Splendid China's parks), a romanticized historical time (the Songcheng parks), local stories (Sunac Land parks), and national cultural stories (the Fantawild Oriental Heritage model). Each of these spaces presents narratives and immersive environments that have the power to engage visitors on physical, sensual, conceptual, and emotional levels. They are second worlds to play in, imagine in, and to consume fantasy in while also providing a shifting model of theme park experience.
\end{abstract}

Keywords: theme parks, China, worldbuilding, subcreation, immersion, culture

China is one of the largest markets in the global theme park industry and it was expected to have the largest attendance in 2020, had the pandemic not interfered with the industry's trajectory (Rubin 44). Perhaps because of a lack of familiarity with the Chinese industry, the most common discussions within scholarship in English have tended towards the arrival of Western brands such as Disney and Universal into China. After exploring concepts of worldbuilding and immersion, this article provides details of several examples of this practice in Chinese theme parks by examining the parks of four major operators. It likewise argues that these fascinating built worlds offer important looks at the translation of culture into physical space and the emerging design practices of Chinese theme park companies. The interpretation of the Western theme park paradigm into the East is a worthy concept to study considering the long-term association of theme parks with Western culture and leisure practices. These parks offer a window into the fascinating act of subcreation in physical space as theme parks are fantastic worlds 


\section{SARE, Vol. 58, Issue $1 \mid 2021$}

in physical space. They also showcase an emerging Chinese design paradigm based on cultural heritage and historical imaginaries.

China's notion of a themed space dates back to the 18th-century Old Summer Palace and its imperial garden (Ren 99). Splendid China, opened in 1989, was the first site designated as a theme park in the new wave of parks (Zhang 412). Theme parks in China were originally created, according to Wen Zhang and Shilian Shan, to express nationalism and to "spread the Chinese traditional culture" (2). Beginning in the 1980s, the Chinese government began a "massive effort to compile items of regional culture such as local opera, storytelling, songs, proverbs, and the like" (McLaren and Zhang 20). This effort has been formalized in physical spaces as well, as there is a government designation of "cultural and tourism villages," so this is further encouragement to design parks with the cultural theme in mind. Yang Lihui explores how folk traditions and stories were impacted by government ideology, but now myths and tales are "an important resource for expressing folk beliefs and educating local communities" and simultaneously lead to more business and tourism (371).

Theme parks have sprung up around the country that tell similar stories though in the more literary tradition of setting a tale into permanence unlike the rich oral tradition's dynamic and location-based tale transformations. History/culture is not only one of the most common themes in current parks, but the "history/culture" concept accounts for more than a quarter of parks under development $(\mathrm{Li} 13,24)$. History and culture in space is considered a "demand trend" and "preference in the market" (Li 24). It will be instructive to observe the kinds of impacts that the parks play in the dissemination of and cementing of cultural beliefs and practices.

\section{Worldbuilding in Theme Parks}

An imaginary world is what envelops fictional characters, creating a "unified sense of place which is ontologically different from the actual, material, and so-called 'real' world" (Wolf 377). Imaginary worlds are built through subcreation, which Mark Wolf defines as the "building of imaginary worlds through the using and recombining of existing concepts and ideas" (381). Immersion is possible for those who consume an imaginary world, with the potential of an audience being "surrounded or engulfed" (377). Wolf identifies levels of immersion possible including physical, sensual, conceptual, and emotional. With physical immersion, the user is "physically surrounded by constructed experience" (377). With sensual, senses like seeing and hearing are part of the "controlled" experience (377). Conceptual immersion, the level focused on imagination, happens when the subcreator can "supply sufficient detail and description for the reader to vicariously enter the imagined world" 
(377). Following immersion in the cognitive area is absorption, a process wherein the audience takes in the new world, "constructing the world within the imagination" (375). "Emotional realism" is necessary in these worlds to lead to empathy and character identification (37). Wolf also references emotional immersion, something possible with absorption and that might lead to saturation, or the "occupying of the audience's full attention and imagination" (49). Like with other similar concepts (flow, presence, engagement, narrative transportation, etc.), the idea is that the audience is at least momentarily captured by a created world to the point that the real world disappears.

At first glance, the concept of the imaginary world may not seem to apply to a theme park, since it has both materiality and real human beings as the acting entities. Theme parks have a long history of being not quite as respected or as seriously considered as other narrative mediums (Williams 11). Nevertheless, theme parks are no doubt imaginary worlds. Worldbuilding and subcreation may be literal in these spaces, but they contain symbolism and fantasies based on never-quite-realities. They are often fantastical or idealized spaces that are certainly separate from the Primary World, our real world, so much so that some critics argue that guests would find these spaces more appealing than the real world. These include postmodern theorist Jean Baudrillard, who found Disneyland to be a "perfect model" for the concept of the simulacrum (with the park more real than the actual world) (12), or sociologist and scholar Sherry Turkle, who explains the "Disneyland effect," where the artificial seems real, and the "artificial crocodile" effect, wherein the fake is "more compelling than the real" because of the power of simulation $(236,237)$. Quite often, theme parks create a unified sense of place, with spaces designed and controlled to eliminate contradictions. Disneyland, which opened in 1955, used the idea of a berm, or a physical separation from the outside world, and designer Joe Rohde argues for the application of details as an "inner berm." Elaborate details in the physical spaces of parks add another layer of separation from the real world according to Rohde; they "uphold the narrative reality" of a story and help guests "surrender" to that story.

A theme park is a product of subcreation and is eminently intertextual. Immersion, one of the vital principles in Wolf, is considered the contemporary paradigm of theme park design. David Younger explains, "In its themed design definition, immersion describes whether the designer intends for the guest to suspend their disbelief and pretend to actually be amongst the fictional world" (86). In more recent attractions around the world, this is in fact the intention of designers. Scott Lukas, is his book on creating immersive worlds, considers "total immersion," a state in which "the guest is taken into another world, story, or place through the use of as many senses as possible," achieved through an "effective combination of symbols, brands, and senses in space" (204). 
Worldbuilding, placemaking, and environmental storytelling are all terms used in the industry. Looking at Wolf's levels of immersion, he notes that theme park rides meet physical immersion criteria (as they tend to employ multi-sensory design) but that they may "still be uninvolving mentally and emotionally" (48). In contemporary theme park experiences, this is less likely to be the case. Theme park lands draw on source material that may be immediately evocative for guests, such as adaptations of well-known imaginary worlds like Harry Potter or Star Wars. Several of the imaginary worlds in Wolf's timeline have been reproduced at theme parks, adding to the notion of transmedia storytelling, or distributing a story across mediums. It is specifically an example of spatial transmedia, or "moments of narrative extension and world-building that take place within specified rooted locations" (Williams 12). The theme park, in this case, is the rooted location where elaborate fantasies play out in simulated yet material spaces. Theme parks rely on this physical worldbuilding, with the affordance of this type of media being the materiality of its world, the ability to traverse physical space, and the movement of visitors in space, allowing them to be fully enveloped by the imaginary world.

Like with other imaginary worlds, the role of the subcreator is essential in theme park design. Henry Jenkins referred to game designers as "narrative architects" who "don't simply tell stories; they design worlds and sculpt spaces" (Jenkins 121). Theme park designers do this but in physical rather than virtual space. The power of this medium is demonstrated through the translation of books, movies, and video games into physical space with lands such as the Wizarding World of Harry Potter, Star Wars: Galaxy's Edge, and Super Nintendo World. Designers shape detailed storyworlds out of architecture, landscaping, music, sounds, lighting, multimedia, live performers, and other elements, creating a synthesis of art forms.

A way designers create a world in space is through environmental storytelling, where instead of worlds existing to "support the stories set in them," the world has "stories embedded in them" (Wolf 29). Environmental storytelling is created through "infusing narrative elements into a world" (377). It is akin to concept of the "design story," a story that is "produced through spatial design" using a variety of elements including "architecture, technology, characters, actors, events, and guests themselves" (Lukas 53). Jenkins lists the possibilities in this kind of storytelling:

Environmental storytelling creates the preconditions for an immersive narrative experience in at least one of four ways: spatial stories can evoke pre-existing narrative associations; they can provide a staging ground where narrative events are enacted; they may embed narrative information within their mise-en-scene; or they provide resources for emergent narratives. (123) 
Theme parks meet all of these preconditions; they are often built with stories that resonate with audiences, they enact narrative daily through a variety of means, they embed narrative within the physical world and in some cases provide a space for new narratives co-created by the guests in time. For example, designers may leave clues for "forensic fans" a la Jason Mittell, who search within multi-layered narratives to find meaning.

The only potential barrier remaining to construct a theme park as an imaginary world would be the idea that these worlds are inhabited by fictional characters. It is true that real live people visit and operate these places. Nonetheless, theme parks are filled with role-playing opportunities, with "story hooks" throughout that encourage visitor participation in narratives (Younger 92). For instance, The Wizarding World of Harry Potter at the Universal theme parks encourages visitors to participate in the magical world through various experiences such as visiting storyworld-specific sites, dressing up in Hogwarts robes, and completing an interactive wand quest. Star Wars: Rise of the Resistance, considered a paragon of ride design, casts the visitor in the role of a Resistance recruit in the vast narrative of the Star Wars film franchise. A mobile application called Star Wars: Datapad further connects people to the ride's mission. The immersive theatre experience Ghost Town Alive! at Knott's Berry Farm allows guests to be involved in the day-to-day life of the town of Calico and presents a branching narrative that gives visitors agency in determining each day's ending. There is a long history of purposeful immersion in these spaces, with everything from an original Disneyland ride, Peter Pan's Flight (1955), which permitted guests to fly through the Disney film's imaginary world, to the much older A Trip to the Moon, a pioneering attraction from the Pan-American Exposition (1901) and then Coney Island's Luna Park (1903), that saw guests flying to and then landing on the moon's surface. More recent immersive experiences and emerging experimental forms include placemaking parks with no traditional rides such as Puy du Fou in France, or Songcheng in China, as discussed below; parks fully built for the purposes of entering a fantasy world and role-playing, like Evermore Park in Utah; or the interactive theatre experiences like Ghost Town Alive! mentioned above.

Finally, theme parks operate as a form of theatre. Jennifer Kokai and Tom Robson conceive of all of the Disney parks as "immersive theatre," with the "tourist as actor" (14). Employees also tend to function as actors in the performance cultures of parks like Disney and Universal that use the language of the stage in employment training. But in most parks, regardless of the type of operator, it is the guest who is cast in myriad fictional roles in one day. In many attractions within a theme park, the guest is brought to another world and generally placed in the role of visitor to that imaginary space if not a participant. Theme parks often function with a "bi-narrative structure," where two levels of storytelling occur at once: the "observable" narrative of external characters going 
through a plot in an attraction, and the "experiential" narrative of the guests going through that attraction (Kay). Some theme park attractions prioritize the guest's storyline, and a few, for example Disney's Avatar Flight of Passage ride, have removed the observable story, making entire attractions about the journey of the rider. Regardless, theme parks will continue to function as living imaginary worlds guests can physically and sensorily experience that often go beyond this to the impactful conceptual and emotional levels. In this article, examples in the Chinese theme park industry were chosen based on my observations of the parks and their embodiment of four concepts I found salient: simulated place, romanticizing historical eras, emphasis on localized history, or a focus on national cultural history.

\section{Simulated Place: Splendid China}

Splendid China (1989) in Shenzhen is a historically significant park, as it signaled the beginning of the leisure industry in mainland China and sparked major economic and socio-cultural changes in the region (Liang and Bao 478). Created as a park to "promote tourism in China," Splendid China is a miniature park, with guests towering over intricate replicas of buildings, landscapes, and people (Zhang 411). The park was inspired by a visit to Madurodam in The Netherlands, a miniature park that Walt Disney drew ideas from. Splendid China's creator, Ma Zhimin, explains:

I was thinking how great it would be if we could build a miniature scenic spot in which China's renowned scenic attractions and historical sites could be concentratedly displayed so that people could admire and know more about China's beautiful scenic wonders, splendid history and culture as well as various national customs and habits in a shorter time. (qtd. in Zhang 412).

The second park in the large, multi-theme park complex, Chinese Folk Culture Villages, recreates villages that represent dozens of ethnic minorities in China. The third park, Window of the World, went away from the Chinese concept to depict international landmarks, similar to Miniland at the Legoland parks, or on a larger scale, Disney's Epcot.

Splendid China is an imaginary world, as it places large swathes of buildings and peoples within one spot, reducing geographical and cultural distances to a single, unified space. It is a story of celebrating one country but contains multitudes of smaller stories that fit within. Wolf clarifies that an imaginary world "can have multiple stories set in it, and need not be dependent on any particular story for its existence" (29). Splendid China's two original parks tell multiple tales in their miniature displays of staged scenes. They showcase implicit stories of 


\section{SARE, Vol. 58, Issue $1 \mid 2021$}

the beauty of architectural structures but also possibly a perception of Chinese society's relationship with nature because of the juxtaposition of architecture and landscaping and the prevalence of green spaces. Xiaolin Duan reflects on China's shift in the relationship with nature including a phase where it focused on gaining resources from the land to "aesthetic appreciation" of nature to the Song Dynasty, when "appreciation of landscape became popularized and commercialized" (5). The relationship with nature in contemporary society is complex, with both ecological crises and a burgeoning of ecocritical approaches and activism (Berman 398). At Splendid China, the natural story is prominent, as every miniature building, regardless of the realities they drew inspiration from, is located within a green garden landscape (see Fig. 1). More obvious storytelling is used in their Chinese Cultural Show, a large stage show with elaborate dance numbers that reference art forms such as jingju and stories like that of the Monkey King.

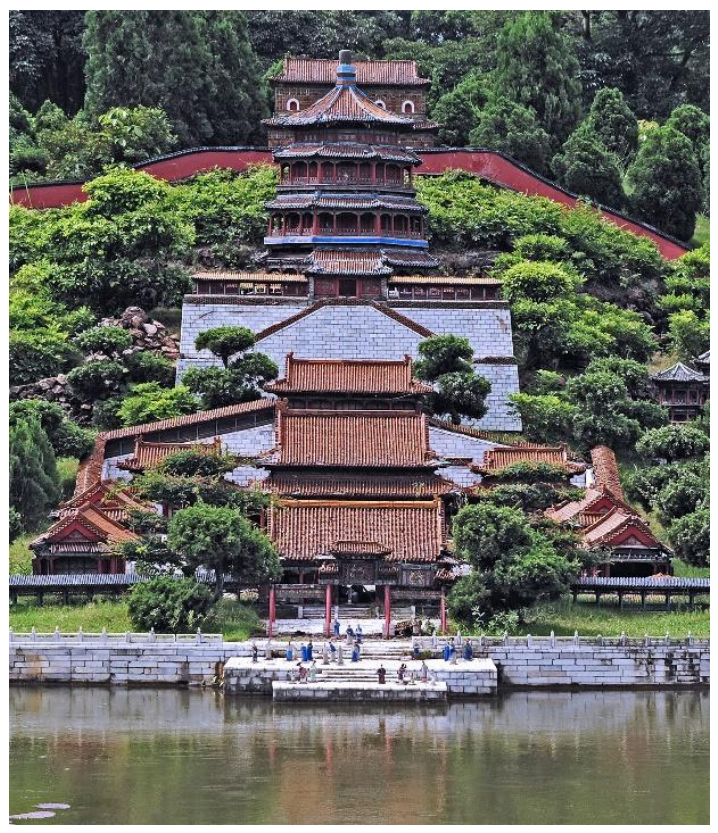

Fig. 1

The inclusion of specific buildings and the addition of symbols for multiple ethnic minorities presents a vision of the most popular landmarks of China. Like with theme parks across the world, certain types of conflict and strife are removed, creating an aesthetically pleasing and idyllic locale for exploration. While the miniature world is visually interesting and aesthetically satisfying for visitors, it is less sensorily engaging and more timeless in its display, making it a near opposite of the Songcheng parks. 


\section{Romanticized Historical Time: Songcheng}

Songcheng, or Song Dynasty Town, opened in Hangzhou (and subsequently, in more than a half dozen cities) in 1996. It is located near the famed West Lake, a "cultural landmark in China since the Song Dynasty" and one of the most visited sites in the country (Duan 3). Unlike the tradition of most amusement and theme parks of relying on rides for appeal, Songcheng emphasizes an immersive experience within the Song Dynasty. Upon entry, a gateway declares it as the "Time Travel Park," and promotional materials emphasize that visiting the park is meant to replicate a typical day during the Song Dynasty. Smaller stage shows (such as a royal procession through the park, a wedding, and a puppet show), Buddhist shrines, and traditional crafts dot the park. Cosplay is strongly encouraged, specifically wearing reproductions of Song fashions and then taking photographs in this attire. The most famous aspect of the park is its epic stage show Romance of the Song Dynasty, which features multiple segments: life in the Song Dynasty, heroism of the Song-era general Yue Fei, the famous stories from the West Lake, and modern life in the city of Hangzhou.

In one of the more interesting features of a theme park, Songcheng is patterned off the important Song-era painting "Along the River during the Qingming Festival” by Zhang Zeduan (1085-1145). The painting itself is simulated in a large-scale digital installation that guests can walk by and watch dynamically shift from day to night (see Figs. 2 and 3). While Duan observes that this painting illustrates people interacting with and appreciating nature, the idea behind the simulation of the painting is to interact with and appreciate the art and zeitgeist of the Song dynasty (121). Though the Qingming Festival is traditionally associated with celebrating ones' ancestors at their gravesites, this element is perhaps strangely removed from prominence in the park's portrayal. One of the Buddhist areas of the park does draw inspiration from the carvings of the Felai Feng grottoes near Lingyin Temple (a site only twenty minutes away from the park), though it is markedly new and obviously concrete. 


\section{SARE, Vol. 58, Issue 1 | 2021}

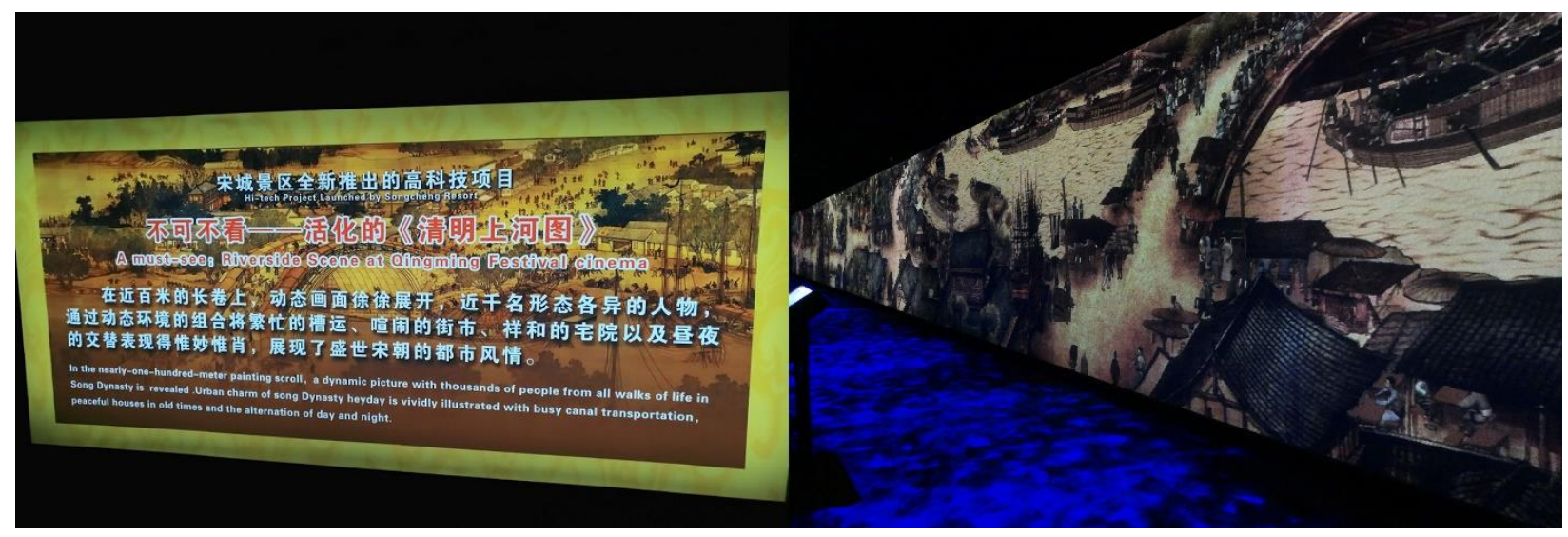

Fig. 2

Fig. 3

Songcheng is all about setting and historical (if fictional) placemaking. Jenkins clarifies that an amusement park does not always "reproduce the story of a literary work" so much as it "evokes its atmosphere" (123). At Songcheng, the exact nature of the Song dynasty or even of the Zeduan painting are not reproduced, but an atmosphere is built. It is plentiful with invention, or the "act of producing elements for a narrative or world," particularly those that "vary considerably from their Primary World counterparts" (Wolf 378). Songcheng tries to recreate a "real world" that once was yet may not have ever been, so it has a different atmosphere from our real world and from many theme parks. Its everyday realities make it a fascinating kind of imaginary world and one of the more participatory worlds in the essay with its emphasis on the guest actually living in the Song historical imaginary.

Duan argues that during the Song Dynasty, the West Lake became a "model for idealized nature" with spiritual and aesthetic desires paramount in the activities of sightseers (4). The Songcheng theme park similarly finds the site a model for idealized history and culture. Because of the references to the Zeduan painting and the Song city of Kaifeng, the park can be read as a hyperreal "double simulation," but it is a "representation that historians argue may never have existed" (Ong and Jin 228). The Songcheng parks go to "extraordinary lengths to simulate scenes of everyday life" of the Song period, but it is nonetheless a "fictional version" of that past (Ludwig and Wang 153, 161). Nonetheless, brand loyalty, or positive associations and continued patronage, to the Songcheng operator is connected with the parks' "historical and cultural performance," ambience, and representation in general; in fact, the historical/cultural theme is "the root of brand attachment" here (Cheng, Fang, and Chen 861, 866). Living in the simulation for a visit is precisely what appeals to guests. 


\section{SARE, Vol. 58, Issue 1 | 2021}

Songcheng is filled with those smaller details that form the inner berm Rohde described. Wolf too mentions the purpose of details: "For works in which world-building occurs, there may be a wealth of details and events... which do not advance the story but provide background richness and verisimilitude to the imaginary world" (2). A real Song-era town would have religious buildings, food cooking in the street, craftspeople, traditional puppet shows (see Fig. 4), and animals walking around, all aspects present in the park. Strolling through the park provides an intimacy with the era, something the stage shows disconnect from in their grand tendencies.

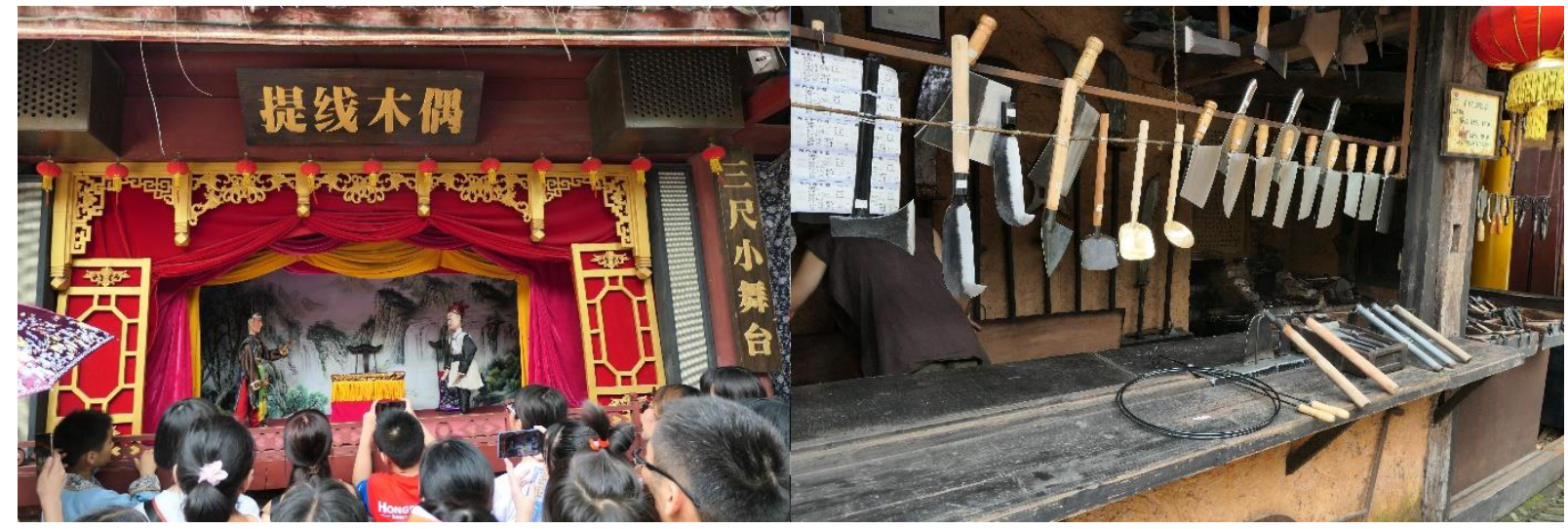

Fig. 4

Fig. 5

Small slice-of-life scenes take place that recall important cultural elements like an official's daughter throwing out a yarn ball to choose a husband, vendors in the crafts districts (see Fig. 5), or small bits of horror such as the haunted house called the Nightmares of Liao Zhai (a famous set of strange tales), all include elements that add to realism.

\section{Local Culture and Histories: Sunac Land}

In the West, there are parks such as Dollywood that focus on a particular area of a country, sites that encompass a nation like Efteling, and amalgam parks that represent a whole region (e.g., Europa-Park) or multiple parts of the world (Epcot). Chinese operators make similar choices when determining the scope of cultural elements in a park. Local culture and tales have been seen in other Chinese operators such as Songcheng and Fantawild, but Sunac theme parks (a handful of which were built and formerly owned by the Wanda Group leisure company), tend to emphasize the region the parks are in. There are more than a dozen parks in the group, including Nanchang 
Sunac Land (2009), Hefei Sunac Land (2016), and Harbin Sunac Land (2017), all of which highlight the customs of the local area and combine these with major attractions. Harbin Sunac Land maintains the Russian influence of the city itself in its architecture and entertainment. Nanchang Sunac Land draws inspiration from the Jianxi Province's long history with pottery making (see Fig. 6). Everything from the signage to the ride motifs are related to pottery, with even the large mall outside the park shaped like a setting of porcelain vases.

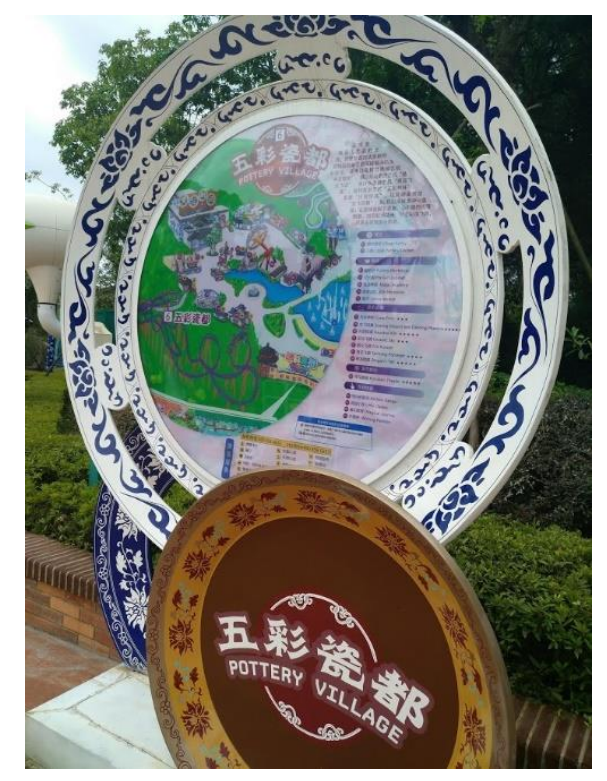

Fig. 6

The focus on local inspirations is evident at Hefei Sunac Land, where the park is differentiated from major operators like Disney because "Chinese culture [was] at the heart of the project" (Holland). According to designer Jan Maarten de Raad, their goal was to "design an environment where culture and heritage come to life through strong story lines and fantasy" (qtd. in Holland). This is specific to the area, as multiple press releases and discussions from the design company Jora Vision refer to the concept of "translating Anhui Province's heritage" to the park (Holland). The places were planned to encapsulate regional culture, as designer Da Wang says, "The whole park is based on the Anhui Province's legends and stories. That was the general concept of Wanda when they started planning parks over different provinces in China. To embrace the Chinese history and Chinese culture." There are signs telling the legends of Chao, a fortress town supernaturally flooded to become a lake, and of the historical dye houses on Wu Lake. An entire theme park land is dedicated to one battle, considered "one of the most important battles in the history of China" (Wang). The Fei River War, or Feishui, was a significant 4th century conflict between the Jin and Qin empire armies where the "underdog" won and ensured independence for 


\section{SARE, Vol. 58, Issue $1 \mid 2021$}

the region. Hefei's showpiece in the land is the "Battle for Fei River" show, an epic outdoor show that includes stunt performance, special effects, and technological effects (see Fig. 7).

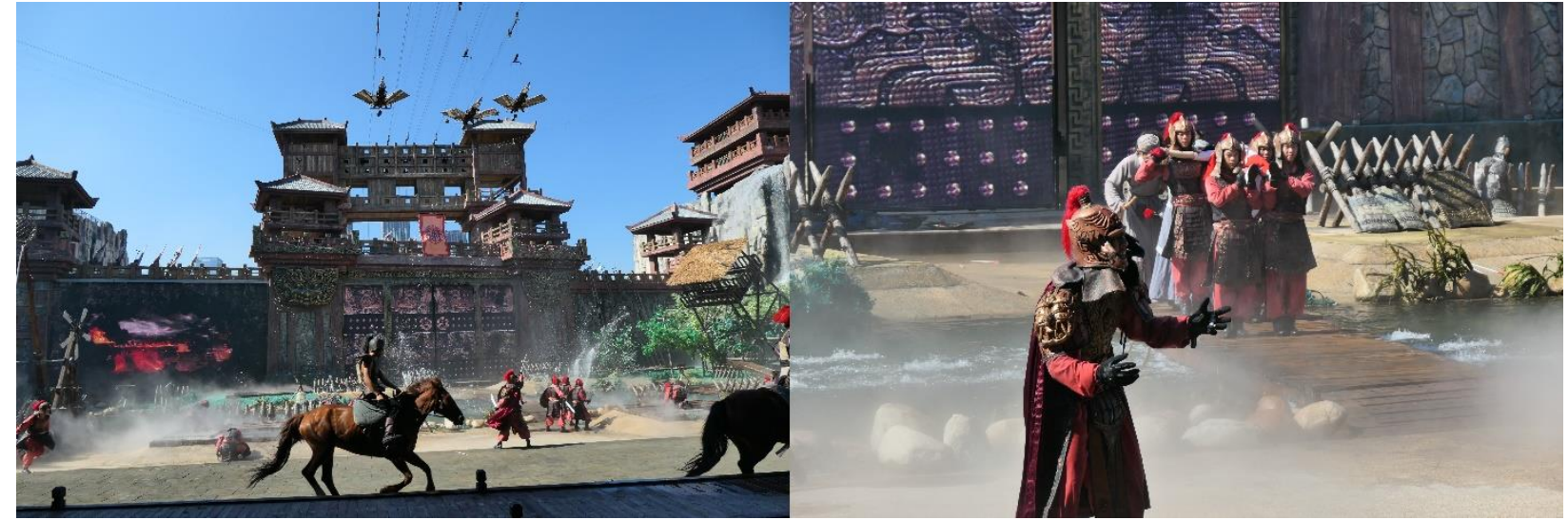

Fig. 7

Fig. 8

The Sunac parks are imaginary worlds, representations of entire regions, with specific architectural or performance icons that indicate this. The Jiangxi region is synonymous with pottery according to the park's creators, so the Nanchang park is filled with pottery décor, a Pottery Village land, pottery-related places like the Haunted Kiln or Potter's Kitchen, and pottery exhibits. The Sunac locations include Chinese fairy tales like "The Cowherd and the Weaving Maiden" and even philosophical content like a written plaque based on the philosophical writings of Zhuang Zhou/Zhuangzi. As with a museum's practice, however, elements of history and culture are chosen and combined, some elements are absent, and several are added for effect. For instance, in the "Battle for Fei River," a romance is added between a general and a noblewoman. The woman is shown in bright colors compared with everyone else, is shown helping needy villagers and fighting, and then is killed by opposing forces, which breaks the heart of soldiers and the people (see Fig. 8). Wang explains that "[t]his is not part of the history. The artist added fiction to make the story more appealing, more relevant for guests." This is a bit of subcreation that augments the real story by emphasizing the human toll of war. This emotional poignancy added to what could have been a dry historical portrayal illustrates the power of worldbuilding and why such details should be transmitted to guests. Though Sunac locations use more common park layouts with multiple themed zones compared to a park with one overall theme like Songcheng, they demonstrate cultural imaginaries in a dimensional environment. 


\section{SARE, Vol. 58, Issue $1 \mid 2021$}

\section{National Cultural Legends: Fantawild Oriental Heritage}

The Chinese operator Fangte, known as Fantawild in English, is considered one of the "best established theme park enterprises in China" and the fifth biggest global operator based on visitation (Chan, Liu, and Li 111; Rubin 11). They had sci-fi and fantasy-themed concepts (Adventure and Dreamland, respectively) until 2015, when they opened Fantawild Oriental Heritage in the cities of Wuhu and Jinan. According to Fantawild executive Daisy Shang, the Oriental Heritage park model is based on "Chinese traditional culture" combined with high technologies and attracts visitors because "China has a long history and there are a lot of stories to tell" (qtd. in "Fantawild Group"). The concept became a blueprint for other parks, and they have now expanded to another half dozen locations in addition to creating offshoot parks like Fantawild Asian Legend.

Looking at the rides and show offerings at Fantawild Oriental Heritage parks, there is no doubt that nationally-valued legends and tales make up the majority of experiences. These include attractions based on the goddess Nüwa, the boy deity Nezha, the famous Monkey King/Sun Wukong, and what are deemed "China's four great folk tales" (Idema 26): "Lady Meng Jiang," "The Cowherd and the Weaving Maiden," "Liang Shanbo and Zhu Yingtai" (often called "Butterfly Lovers"), and "Legend of the White Snake." Wilt Idema considers the continual reproduction through various technologies of these tales a sign that audiences long for a "traditional China that would never return" (43). Visitors deem Fantawild parks unique precisely because of their "inclusion of Chinese traditional cultural elements" (Xu et al. 331). Experiences mentioned by guests include attractions based on the "White Snake" story (called at Fantawild parks The White Snake Maiden's Fury or Jinshan Temple Showdown) and the tomb of the first Qin emperor (Qin Dynasty Adventure).

One great example of the park's ethos is the large, slow-moving dark ride named Chinese Opera Express (see Figs. 9 and 10). This entire ride is based on jingju, or Beijing opera, with guests being immersed in each scene of an ornate opera performance. This is an assertion of traditional Chinese culture, as Chinese drama (xiqu), particularly jingju, "remained popular throughout the centuries" (Qi and Zhang 5). However, in the last few decades, it has gotten a "depressingly smaller market share" due to the many genres of entertainment and technological platforms now available to audiences (5). In this attraction, a traditional art form is staged with high technologies and in a theme park model that is less than a decade old. 


\section{SARE, Vol. 58, Issue 1 | 2021}

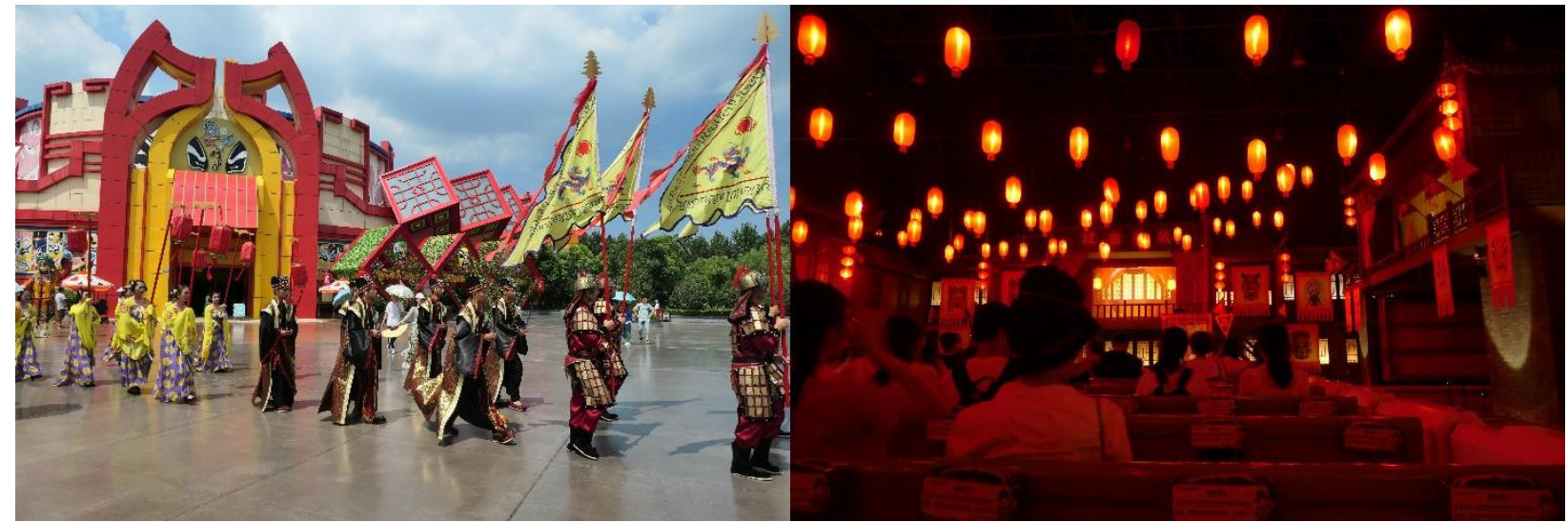

Fig. 9

Fig. 10

Unlike Songcheng, Fantawild does not attempt to stage the past with immersive elements or slice-of-life reenactment; it creates a new space entirely that is part Chinese architecture and landscaping, part high technology rides and shows, and part a recall of aspects of Chinese cultural history. It is a mix of old stories and new technologies, presenting an imaginary world that feels different from other theme parks.

Conceptually, Oriental Heritage advances the imaginary world of the Chinese theme park in a more contemporary way than most parks. It was conceived as a brand to showcase Chinese culture with high-quality attractions, primarily stage shows and elaborate dark rides. Their own proprietary technology, a domed theatre in the round where seats lift into the air during key moments in a storyline, has been used to tell tales of the Monkey King and "The Cowherd and the Weaver." The narratives at the park are generally epic and immense. The White Snake Maiden's Fury attraction combines a lengthy, boat-based dark ride with live actors, projection mapping, and a stage show finale on a larger scale than most Western theme parks offer.

\section{Theme Parks and Cultural Worldbuilding}

Theme parks exist as Secondary Worlds, imaginary worlds that stand apart from our real, Primary World; discovering a subcreated, imaginary world sparks the use of our "secondary imagination," which lets us "picture what does not exist" (Wolf 381). The hyperreal simulations of theme parks make it easy to visualize an imaginary world. However, since these spaces exist in the material world, strong design is needed to provide verisimilitude, or it is impossible to suspend disbelief. Of all the parks in this essay, Songcheng is the most environmentally immersive imaginary world. Splendid China might be considered prettier, the Sunac parks more thrilling, and the Fantawild parks more technological. Songcheng is human-scaled, unlike Splendid China where humans tower 


\section{SARE, Vol. 58, Issue $1 \mid 2021$}

above landscapes or the other two, where landscapes tower above humans. All of them, however, deliver a subcreated world to visitors who want to "transcend their everyday experience" (Hench 9).

Like all story-driven theme parks, Chinese sites require guests to want to engage with, immerse in, and absorb a real experience in a fictional world. This is easier to do with perceived authenticity, something that may be more likely with attempted reproductions of history and culture. These kinds of spaces provide audiences a palpable link to the past but allow for a playful and fanciful relationship with it rather than a gritty one based on wholly historical realities. The translation of cultural tales into theme park attractions and the influence of culture on theme park design has long been remarked on, with Margaret King calling theme parks "cultural narratives" and an "index to culture in themselves" (6). Whether Disneyland in the United States, Efteling in Europe, or Songcheng in Asia, the same pattern is found: the pull of culture encased in wonderment, or the signature of the theme park.

Creating cultural metaphors through the form of a theme park is not a task without complications. Salvador Anton Clavé states that the development of theme parks with a cultural theme, especially if they wish to "take root in the identity of the place where they are located," translates into the "construction of ideological discourses in the heart of the local communities themselves" (263). With all theme parks, local communities are impacted by their existence in economic, cultural, and social ways. Ethnic minority-based culture parks can demonstrate "cultural diversity as a good" but can also cause tension through stereotyped identities (263). These are both on display in a park like Yunnan Ethnic Folk Villages in Kunming, a popular site meant to "exhibit diverse cultures, traditions and the ways of life of minorities" (Yang, "Minorities" 317). A park such as this has both the negative potential of misrepresentations of minority cultures and the ability to stimulate interest in learning more about ethnic minorities and visiting real villages (Yang "Minorities," Yang "Cultural”). Cultural parks are known to generate economic benefits and help sustain practices; nonetheless, according to Li Yang, there is a concern that representatives of the majority culture (Han Chinese) are in control as managers, with "cultural assimilation" a dominant concern within society and tourism ("Minorities" 330). Representations may be from the perspective of designers who may not be part of a minority culture or may reflect a government-approved message. Katharina Massing finds that a park with a similar function, the Binglang Ethnic Village (or Binglanggu) in Sanya, can be viewed as staging, commercializing, and fossilizing culture but that it may also play a role in "safeguarding intangible cultural heritage," especially for minority traditions that are fading due to rapid modernization and urbanization (66). Similar to Yang, Massing contends that the Han majority controls the narrative and that 


\section{SARE, Vol. 58, Issue $1 \mid 2021$}

minorities do not get to "show alternative representations" (68). China will continue to try to preserve particular aspects of cultures with the staged space of the theme park, so a debate remains.

Unlike in most major Western parks, religion is tackled openly in Chinese parks. Many parks enact stories or use iconography from Buddhist, Taoist, folk religion, and occasionally Confucian traditions. Some, like Songcheng as noted, have temples and shrines within the park (see Fig. 11). Splendid China has a scale model of the Leshan Giant Buddha. Fantawild Oriental Heritage parks tend to have religious icons such as Buddha statues and the Devil's Peak ride, based on the monk Xuan Zang, is filled with Buddhist imagery. Nezha and Nüwa have roles in rides at multiple parks. Thus, it is not only prominent Chinese folk tales on display but key stories connected with Chinese philosophies and beliefs that appear in these theme parks. The Lingshan Buddhist Scenic Spot near Wuxi illustrates a blurring of the concept of theme park or religious site. A contemporary religiousfocused space, it has many of the trappings of a theme park including its layout, themed zones (sections for Buddhist expressions from different countries), commercial souvenirs, mascot, and a stage show with effects (see Fig. 12).

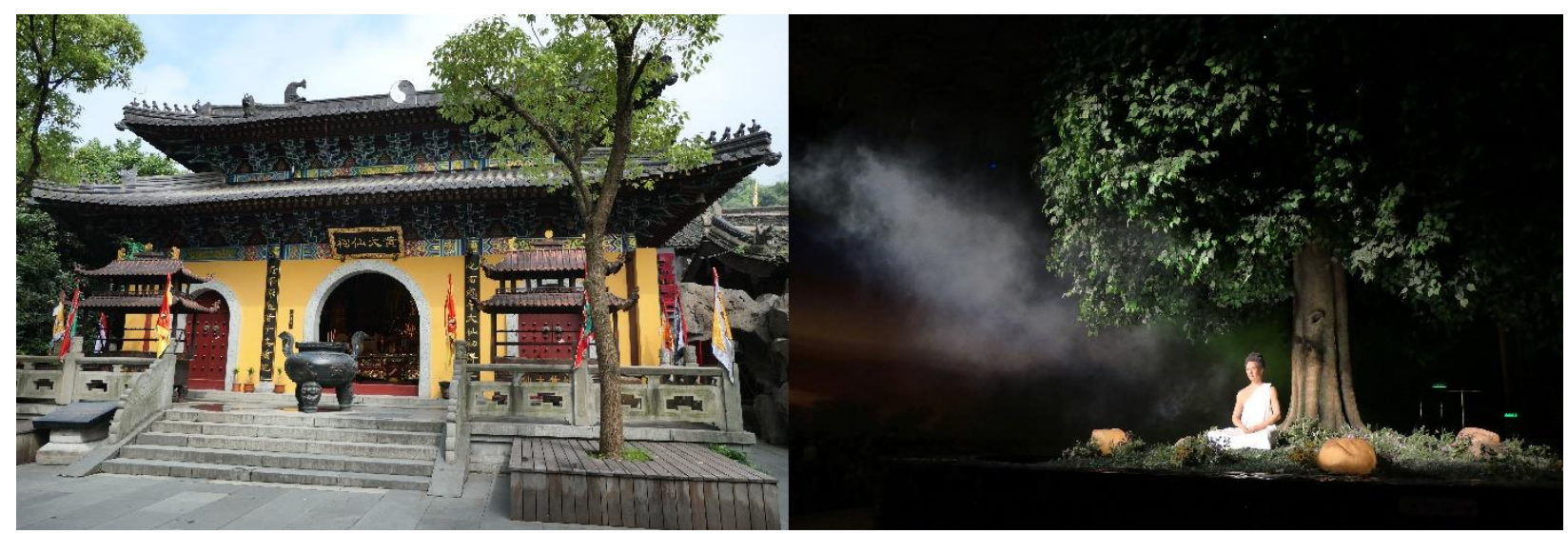

Fig. 11

Fig. 12

Depictions of religion can also be complicated. A copy of Angkor Wat at the Fantawild Asian Legend Park (in Nanning), for example, caused negative feelings in some Cambodians hearing that "their historic and religious landmark had been replicated and placed in a theme park" (Spiess). However, theme parks have long had components of the sacred and have been recognized for their similarities to pilgrimage sites or spaces of myth and ritual (Moore; Kottak). Religious depiction also contributes to authenticity in cultural parks. Qian Cheng, Lin Fang, and Huazhen Chen note, "Unique cultural characteristics are the essence of historical and cultural theme parks. In contrast to other categories of theme parks, the fascinating elements of folklore and customs should 


\section{SARE, Vol. 58, Issue 1 | 2021}

permeate historical and cultural theme parks" (867). An immersive space like Songcheng, where Buddhist shrines intermingle with the mundane, would be less convincing without religious iconography. Guests in China may additionally want "spiritual value" in a park, and recreation can be related to the "spiritual experience of visitors" (Cheng, Guo, and Ling 908). It is apparent that visitors making spiritual connections in a theme park have moved to those cognitive/emotional levels of immersion.

A final consideration is the emerging paradigm of the Chinese-created theme park fantastic. Discussion of parks in scholarship still tends to focus on the "perceived Euro-American origin of theme parks" (Erb and Ong 145). Maribeth Erb and Chin-Ee Ong find that theming played a major role in creating a "specific spatial and social form" that has now transformed Asia with major parks in Japan, Korea, and China (143). Designed spaces like theme parks, they argue, play a role in "ordering our social worlds" (143). Erb and Ong observe that the Asian understanding of the past is different from the West's, so the common arguments about simulation and copy (particularly common to cultural studies and postmodern readings of theme parks as texts) are less accurate. The rebuilding of a pagoda in China is not less authentic; it is instead an "ongoing production of their culture" (159). Likewise, as is demonstrated by the satisfaction with the Songcheng parks, an average guest not only does not find the simulation troubling, they connect to the brand because of it (and there must be an assumption that many visitors make choices about and interpret the spaces they consume). Fantawild Oriental Heritage especially showcases an evolving understanding of theme park design that asserts a Chinese mode of creating this genre of experiences.

There are several things that are worth considering about Chinese theme parks, especially as they become part of the most visited market in the global industry (Rubin 49). Chin-Ee Ong asserts that Chinese theme parks are "key nodes in our understanding of leisure and tourism spaces and of middle-class landscapes in contemporary China" (188). They provide windows into an evolving culture of leisure and potential new models in the conception of the theme park. They illustrate the imaginary world created in physical space and how this differs due to local, regional, and national contexts. These spaces are not only constructed as adaptations of great stories and entertainment for their multi-generational guests. They recreate historical imaginaries and cultural fantasies that guests can enjoy to the point of saturation.

Wolf extols subcreation as a "need and right," as something that "renews our vision and gives us new perspective and insight into ontological questions that might otherwise escape our notice" (287). Focusing on subcreated worlds, whether classic literature or contemporary theme parks in China, helps us ask questions about 


\section{SARE, Vol. 58, Issue $1 \mid 2021$}

our histories, our cultural practices, and our human need for visions of other worlds. In what ways do theme parks depict our pasts or our values? How do we practice leisure in theme parks? How are cultures presented in the imaginary worlds of theme parks? Who writes or curates the stories in these spaces? What stories matter to our understanding of ourselves? Why are we so fascinated by built worlds? Which fantasies do we prefer to play in or live in for a day? Theme parks in general are rife for these kinds of explorations, but China is an especially intriguing location because of its rapid shift to a leisure economy, its soon to be market dominance, and its development of a new theme park model after so many decades of a different paradigm. The parks provide a contemporary society with palpable links to the past and represent an assertion of cultural relevance in an industry that has been dominated by the West for more than a century. They are also exemplars of a newer form of fantastic imaginary in China. In these second worlds, we can walk in and then explore, having been transported to "fantastic realms culled from endless possibilities" (Wolf 1). Theme parks have been shown to be highly inspirational sites to the fandoms that follow them, but they inspire the average visitor as well. Once at home, guests may consider their time in the subcreated space and build their own worlds, combining dream material with inspirations from their time in these fascinating, physical imaginary worlds.

\section{Works Cited}

Baudrillard, Jean. Simulacra and Simulation. 1981. Translated by Sheila Faria Glaser, U of Michigan P, 1994. Berman, Douglass Scott. “Chinese Ecocriticism: A Survey of the Landscape.” Literature Compass, vol. 12, no. 8, 2015, pp. 396-403.

Chan, Chung-Shing, Yumeng Liu, and Ching Yeung Li. "Expectation-Perception Evaluation of Theme Park Service Quality in Zhengzhou Fantawild, China.” Journal of Park and Recreation Administration, vol. 37, no. 2, 2019, pp. 99-117.

Cheng, Qian, Jingjing Guo, and Supei Ling. "Fuzzy Importance-Performance Analysis of Visitor Satisfaction for Theme Park: The Case of Fantawild Adventure in Taiwan, China." Current Issues in Tourism, vol. 19, no. 9, pp. 895-912.

Cheng, Qian, Lin Fang, and Huazhen Chen. "Visitors' Brand Loyalty to a Historical and Cultural Theme Park:

A Case Study of Hangzhou Songcheng, China." Current Issues in Tourism, Vol. 19, no. 9, 2016, pp. 861868.

Clavé, Salvador Anton. The Global Theme Park Industry. CABI, 2007. 


\section{SARE, Vol. 58, Issue $1 \mid 2021$}

Duan, Xiaolin. The Rise of West Lake: A Cultural Landmark in the Song Dynasty. U of Washington P, 2020.

Erb, Maribeth, and Chin-Ee Ong. "Theming Asia: Culture, Nature and Heritage in a Transforming Environment." Tourism Geographies, vol. 19, no. 2, 2017, pp. 143-167.

"Fantawild Group.” ParkWorld, 16 Nov. 2015, www.parkworld-online.com/fantawild-group/.

Hench, John. Designing Disney: Imagineering and the Art of the Show. Disney Editions, 2009.

Holland, Jason. "Details of Wanda Group's Chinese Cultural Theme Park Unveiled.” Spa Business, 1 May 2014, www.spabusiness.com/wellness-news/Details-of-Wanda-Groups-Chinese-cultural-theme-parkunveiled/309144.

Idema, Wilt. “Old Tales for New Times: Some Comments on the Cultural Translation of China's Four Great Folktales.” Taiwan Journal of East Asian Studies, vol. 9, no. 1, 2012, pp. 25-46.

Jenkins, Henry. “Game Design as Narrative Architecture.” First Person: New Media as Story, Performance, and Game, edited by Noah Wardrip-Fruin and Pat Harrigan, MIT P, 2004, pp. 118-129.

Kay, Ian. "Bi-Narrative Structure.” Pure Imagineering: Theme Park Narratology. 17, Sept. 2013, pureimagineering.blogspot.com/2013/09/experiential-and-presentational-stories.html.

King, Margaret. "The Theme Park: Aspects of Experience in a Four-Dimensional Landscape," Material Culture, vol. 34, no. 2, 2002, pp. 1-15.

Kokai, Jennifer and Tom Robson. "You're in the Parade! Disney as Immersive Theatre and the Tourist as Actor." Performance and the Disney Theme Park Experience: The Tourist as Actor, edited by Jennifer Kokai and Tom Robson, Palgrave Macmillan, 2019, pp. 3-20.

Kottak, Conrad Phillip. Cultural Anthropology. McGraw Hill, 1994.

Li, Shaojin, ed. China Theme Park Pipeline Report. AECOM, 2018.

Liang, Zeng-Xian, and Ji-Gang Bao. "Tourism Gentrification in Shenzhen, China: Causes and Socio-Spatial Consequences.” Tourism Geographies, vol. 17, no. 3, 2015, pp. 461-481.

Lihui, Yang. "The Effectiveness and Limitations on 'Context': Reflections Based on Ethnographic Research of Myth Traditions.” Asian Ethnology, vol. 74, no. 2, 2015, pp. 363-377.

Ludwig, Carol, and Yi-Wen Wang. "Open-Air Museums and Historical Theme Parks in the UK and China." The Heritage Turn in China: The Reinvention, Dissemination and Consumption of Heritage, edited by Carol Lugwig, Linda Walton, and Yi-Wen Wang. Amsterdam UP, 2020, pp. 131-168.

Lukas, Scott. The Immersive Worlds Handbook. Focal Press, 2013. 


\section{SARE, Vol. 58, Issue $1 \mid 2021$}

Massing, Katharina. "Safeguarding Intangible Cultural Heritage in an Ethnic Theme Park Setting: The Case of Binglanggu in Hainan Province, China.” International Journal of Heritage Studies, vol. 24, no. 1, 2018, pp. 66-82.

McLaren, Anne E., and Emily Yu Zhang. "Recreating 'Traditional' Folk Epics in Contemporary China: The Politics of Textual Transmission." Asian Ethnology, vol. 76, no. 1, 2017, pp. 19-41.

Mittell, Jason. "Forensic Fandom and the Drillable Text.” Spreadable Media, 2013, spreadablemedia.org/essays/mittell/index. html\#.X0bapshKhnI.

Moore, Alexander. "Walt Disney World: Bounded Ritual Space and the Playful Pilgrimage Center. Anthropological Quarterly, vol. 53, no. 4, 1980, pp. 207-218.

Ong, Chin-Ee. “'Cuteifying' Spaces and Staging Marine Mammals for Chinese Middle Class Consumption.” Tourism Geographies, vol. 19, no. 2, 2017, pp. 188-207.

Ong, Chin-Ee, and Ge Jin. "Simulacra and Simulation: Double Simulation at a North Song Dynasty Theme Park." Tourism Geographies, vol. 19, no. 2, 2017, pp. 227-243.

Qi, Shouhua, and Wei Zhang. "Tragic Hero and Hero Tragedy: Reimagining Oedipus the King as Jingju (Peking Opera) for the Chinese Stage.” Classical Receptions Journal, vol. 11, no. 1, 2019, 1-22.

Ren, Hai. “The Landscape of Power: Imagineering Consumer Behavior at China's Theme Parks.” The Themed Space: Locating Culture, Nation, and Self, edited by Scott Lukas, Lexington Books, 2007, pp. 97-112.

Rohde, Joe. “Details: The Inner Berm.” Instagram, 5 May 2017. https://www.instagram.com/p/BTugAK_AoZN/.

Rubin, Judith, Ed. Global Attractions Attendance Report 2019. TEA/AECOM, 2020.

Spiess, Robin. "Chinese Theme Park Risks Offending Cambodians with Angkor War Replica." Southeast Asia Globe, 19 Sept. 2018, sea-globe.com/chinese-theme-park-risks-offendingcambodians-with-angkor-wat-replica/.

Turkle, Sherry. Life on the Screen: Identity in the Age of the Internet. Simon \& Schuster, 1995.

Wang, Da. Personal interview. 1 Oct. 2020.

Williams, Rebecca. Theme Park Fandom: Spatial Transmedia, Materiality, and Participatory Cultures. Amsterdam UP, 2020.

Wolf, Mark. Building Imaginary Worlds: The Theory and History of Subcreation. Routledge, 2012. 


\section{SARE, Vol. 58, Issue $1 \mid 2021$}

$\mathrm{Xu}$, Jing (Bill), Erdogan Ekiz, Wei Yuan, and Doris Shuk-ting Lo. "How Can a Regional Theme Park Survive in China?: Studying Strategies Used by Fantawild Dreamland. Emerging Innovative Strategies in the Tourism Industry, edited by Nilanjan Ray. IGI Global, 2014, pp. 322-338.

Yang, Li. "Cultural Representation in the Yunnan Ethnic Folk Villages." Travel and Tourism Research Association: Advancing Tourism Research Globally, vol. 14, 2016.

Yang, Li. “Minorities, Tourism and Ethnic Theme Parks: Employees' Perspectives from

Yunnan, China.” Journal of Cultural Geography, vol. 28, no. 2, 2011, pp. 311-338.

Younger, David. Theme Park Design and the Art of Themed Entertainment. Inklingwood Press, 2016.

Zhang, Wenxian. "A Splendid Idea in China Turned Sour in Florida: The Rise and Fall of the Florida Splendid China." Florida Historical Quarterly, vol. 84, no. 3, 2006, pp. 411-442.

Zhang, Wen, and Shilian Shan. “The Theme Park Industry in China: A Research Review.” Cogent Social Sciences, vol. 2, 2016, pp. 1-17. 